\title{
OPTIMIZED METHOD OF BOVINE PERICARDIUM DECELLULARIZATION FOR TISSUE ENGINEERING
}

DOI: 10.36740/WLek202104101

\author{
Nataliia V. Shchotkina ${ }^{1,2}$, Anatoliy A. Sokol', Oleksandr Yu. Galkin², Glib I. Yemets', Liudmyla V. Dolinchuk², \\ Nadiya M. Rudenko' ${ }^{1}$, liiia M. Yemets ${ }^{1}$ \\ 'CENTER FOR PEDIATRIC CARDIOLOGY AND CARDIO SURGERY, KYIV, UKRAINE \\ "NATIONAL TECHNICAL UNIVERSITY OF UKRAINE"IGOR SIKORSKY KYIV POLYTECHNIC INSTITUTE", KYIV, UKRAINE
}

\begin{abstract}
The aim: To investigate the effectiveness of using low concentrations of sodium dodecyl sulfate (SDS) and cross-linking with EDC/NHS in the decellularization process to create a potential bioimplant for cardiac surgery.

Materials and methods: Pericardial sacs were derived from 12-18 months bulls. Tissue decellularization was performed by using $0.1 \%$ SDS with the following EDC/NHS cross-linking. The experiment included standard histological, microscopic, molecular genetic and biomechanical methods. Scaffold was tested in vitro for cytotoxicity and biocompatibility.

Results: A high degree of extracellular decellularized matrix purification from cells and their components was shown. Structure-function properties remained similar to those or even improved after the decellularization. During prolonged contact of BP with human fibroblasts, no cytotoxic effect was observed. The biointegration of the scaffold in laboratory animals tissues was noted confirming the potential possibility of the implant use in cardiac surgery.

Conclusions: Decellularization of BP by $0.1 \%$ SDS with NHS/EDC cross-linking is promising in manufacturing of the tissue-engineered materials in cardiac surgery.
\end{abstract}

KEY WORDS: tissue engineering, cardio implant, xenograft, bovine pericardium

Wiad Lek. 2021;74(4):815-820

\section{INTRODUCTION}

Biotechnological progress is closely related to the development and introduction into clinical practice of biological materials from xenografts. Decellularized tissues are widely used in the reconstructive surgery. For more than five decades, xenografts have been widely used both in pediatric and adult heart surgery and blood vessels for the correction of acquired and congenital heart defects [1].

Nowadays, one of the most common types of bioimplants is the pericardial patch (scafold) - a collagen matrix of calf pericardium which is either purified from cells by decellularization or structurally stabilized with glutaraldehyde. For the decelularization of pericardium high efficiency of detergents, including ionic detergent sodium dodecyl sulfate (SDS) has been proven [2]. However, these agents should be used at low concentrations to reduce alterations in the ultrastructure of the extracorporeal matrix and maintain glycosaminoglycan (GAG) concentrations [3]. Also, there are some difficulties in using glutaraldehyde, which purifies the tissue and is used to form new covalent bonds between two polymer chains to strengthen the structure of the matrix. Incomplete elimination of residual glutaraldehyde prior scaffold implantation can cause cytotoxic effects on human cells and late calcification of scaffold in vivo [4].

Fixedy by glutaraldehyde pericardial tissue is commonly used for commercially available xenograft valve implants and has proven durability but lacks the capability for re- modelling and growing. Decellularized bovine pericardial tissue is promising to outperform fixed tissue and able to remodel [5]. Thus, the task arose to find a way to create an optimal bioimplant. In this work, it was proposed to test an optimized technique for decellularization and glutaraldehyde-free stabilization of the bovine pericardium matrix.

\section{THE AIM}

The aim of this study was to investigate the effectiveness of using low concentrations of SDS in the decellularization and cross-linking with EDC/NHS for fixation to create a potential bioimplant for cardiac surgery.

\section{MATERIALS AND METHODS}

\section{THE PROCEDURE FOR TISSUE OBTAINING}

The material for the study was the bovine pericardium (BP). The pericardial sac was extracted from outbred 12-18 month old bulls after slaughter at the "Antonivskii Meatplant Ltd." The research was performed in accordance with the General Ethical Principles of Animal Experiments (Strasbourg, France, 1985) and Law of Ukraine No. 3447 - IV On Protection of Animals from Cruel Treatment (2006, edited in 2009). The biomaterial was transported to the laboratory for one hour in a sterile Hanks solution 
in a container on ice. Pericardial sacs were dissected and non-fibrous components were removed. The tissue samples were cut in $40 \times 40 \mathrm{~mm}$. Samples were placed in distilled water in a volume of $1000 \mathrm{ml}$ and stirred continuously (70 rpm) for 3 hours at $4{ }^{\circ} \mathrm{C}$.

\section{GLUTARALDEHYDE-FREE DECELLULARIZATION OF THE BOVINE PERICARDIUM}

BP samples were decellularized as follows: (1) osmotic shock was caused by placing samples into the sterile distilled water ( 5 pieces per $500 \mathrm{ml}$ solution) at $4^{\circ} \mathrm{C}$ for 72 hours $(200 \mathrm{rpm})$. Water was changed every $6-8$ hours; (2) decellularization with $100 \mathrm{ml}$ of $0.1 \%$ solution of SDS (Sigma-Aldrich, USA) with constant shaking (200 rpm) for 35 days at $24^{\circ} \mathrm{C}$; (3) washed with sterile $\mathrm{NaCl}$ solution for 7 days at $4{ }^{\circ} \mathrm{C}$ with constant stirring at $200 \mathrm{rpm}$; (4) stabilization and fixation in a solution of $70 \%$ ethanol for $24 \mathrm{~h}$ at t $4{ }^{\circ} \mathrm{C}$ with constant stirring at $200 \mathrm{rpm}$; (5) washed with sterile $\mathrm{NaCl}$ solution for $24 \mathrm{~h}$ at $4{ }^{\circ} \mathrm{C}$ with constant stirring at $200 \mathrm{rpm}$; (6) cross-linking method [6] - EDC/NHS solution - MES (10 mM 1-Ethyl-3- (3-dimethylaminopropyl) carbodiimide hydrochloride (EDC), 10 mM N-Hydroxysuccinimide) and MES solution ( $\mathrm{pH}$ 5.6) (0.05 M 2-morpholinoethane sulfonic acid); (7) washed with sterile $\mathrm{NaCl}$ solution for $24 \mathrm{~h}$ at $4{ }^{\circ} \mathrm{C}$ with constant stirring at $200 \mathrm{rpm}$. Non decellularized pericardial tissues were chosen as control.

\section{BIOMECHANICAL TESTING}

The biomechanical properties of BP with a size of $20 \times 40$ $\mathrm{mm}$ were analyzed. A test machine (IMADA, MX2 - 110, Japan) was used to determine the maximal tensile strength $\left(\mathrm{F}_{\max }\right)$.

\section{DNA TEST}

DNA extraction was performed with Easy Blood and Tissue DNA kit (Qiagen, Germany). 10-25 mg of tissue from external materials before decellularization or from decellularized samples, were briefly treated with proteinase $\mathrm{K}$ to quantify the total amount of nucleic acid (ng/mg of dry tissue) and the percentage of DNA removal after decellularization. Fluorescence measurements (photons per second) were performed at room temperature $\left(23-24^{\circ} \mathrm{C}\right)$ using a spectrofluorometer Qubit 3.0. The DNA detection limit was $0.2 \mathrm{ng} / \mu \mathrm{g}$ of nucleic acid.

\section{CYTOTOXICITY IN VITRO TESTING}

To determine cytotoxicity the matrix samples were cultured in a suspension of human fibroblasts. 5 fragments from each sample were cut from the obtained material (approximately $8-10 \mathrm{~mm}^{2}$ ). Cells were inoculated by applying $150 \mu$ of concentrated cell suspension $\left(3 \times 10^{5}\right)$ on moistened with standard growth medium (DMEM + 10\% of serum) decellularized pericardial samples. Impregnation lasted 30 minutes. Cells were then transferred to a standard 6-well tissue culture plate and immersed in growth medium DMEM $+10 \%$ of serum. Cultivation was performed under standard conditions of $37^{\circ} \mathrm{C}$ and $5 \%$ of $\mathrm{CO}_{2}$ [7]. For histological examination, DEM samples were fixed in $10 \%$ buffered formalin embedded in paraffin. Sections were made $(5 \mu \mathrm{m})$. Hematoxylin/eosin stained samples were obtained (light microscopy) [8]. Images were taken using an Olympus BX 51 light microscope (Tokyo, Japan).

\section{BIOCOMPATIBILITY TEST IN VIVO}

Ten 4-5 month old male Wistar rats weighing 190-230 g were kept in a pathogen free environment. Decellularized and sterilized bovine pericardium were implanted subcutaneously into the dorsal skin of rats and explanted after 3 months. The animals were divided into the following groups: Control Group - native bovine pericardium $(n=5)$, Group 1 - decellularized bovine pericardium with $0,1 \%$ SDS and cross-linked bovine pericardium $(n=5)$.

The surgical field was shaved and cleansed with a 70\% solution of ethyl alcohol. The surgery was performed in a sterile conditions. Intramuscular anesthesia was used with xylazine (Alfasan, the Netherlands) at a dose of $1 \mathrm{mg} / \mathrm{kg}$ body weight in combination with ketamine (Biolik, Ukraine) at a dose of $10 \mathrm{mg} / \mathrm{kg}$. A $2 \mathrm{~cm}$ incision was performed in the dorsal skin and subcutaneous pockets were formed using a pointed spatula, separating the subcutaneous tissue from the muscular layer. Prepared $1 \times 1 \mathrm{~cm}$ implants were placed in the pocket, which were fixed at the corners to the muscle tissue using „Catgut Chrome“ („Golnit“, Ukraine). Skin was sutured and treated with an antiseptic solution of $1 \%$ „Diamond Green“ („Halychpharm“, Ukraine). Implants were isolated for histological analysis after 3 months post-operation. Euthanasia was perfomed with ether.

\section{HISTOLOGICAL ANALYSIS}

Segments of non decellularized $(n=10)$ and decellularized $(n=10)$ pericardial tissues were fixed in $10 \%$ neutral buffered formalin (Sigma-Aldrich, USA) for $1 \mathrm{~h}$, embedded in paraffin, cut into $5-\mu \mathrm{m}$ sections and stained with hematoxylin \& eosin (H\&E, Sigma Aldrich, USA), Congo red (Congo Red Kit, Sigma Aldrich, USA) and Massons Trichrome stain (MT, Sigma Aldrich, USA). The stained samples were examined with Olympus BX 51 light microscope (Tokyo, Japan).

For scanning electron microscopy (SEM), samples of decellularized pericardium were dried by lyophilization at a vacuum depth of 30-50 $\mathrm{Pa}$ and a temperature of $-50^{\circ} \mathrm{C}$. (JFC-1100, Jeol, Tokyo, Japan). In order to eliminate the accumulation of surface charge during scanning with an electron beam in a microscope column, a thin layer of gold was applied to the dried samples by cathodic sputtering (JFC-1100, Jeol, Tokyo, Japan). The preparations were investigated in SEM JSM 6060 LA (Jeol, Tokyo, Japan) in the secondary electron mode at an electron acceleration voltage of $30 \mathrm{kV}$. 

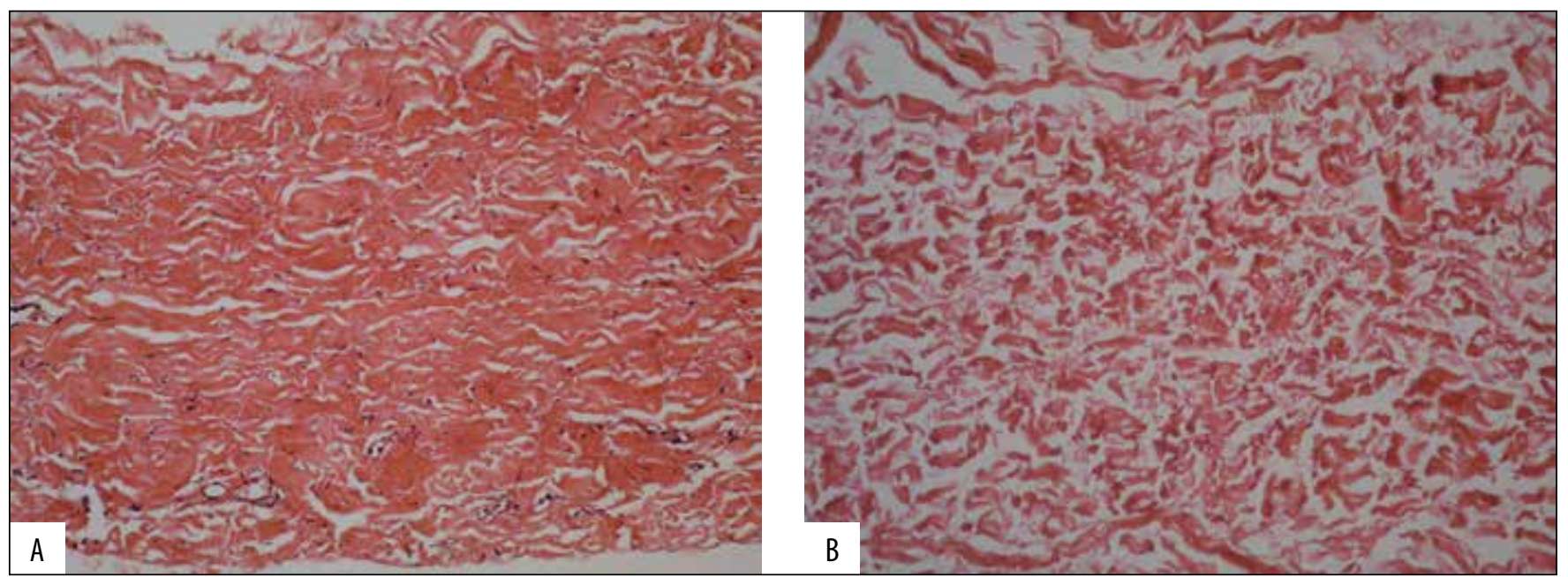

Fig. 1. Micrographs of histological sections of native and decellularized bovine pericardium; hematoxylin/eosin staining, light microscopy, x200. A - presence of visible violet cell nuclei in native bovine pericardium (control group); $B$ - absence of visible cell nuclei in BP decellularized by $0.1 \%$ SDS (experimental group).

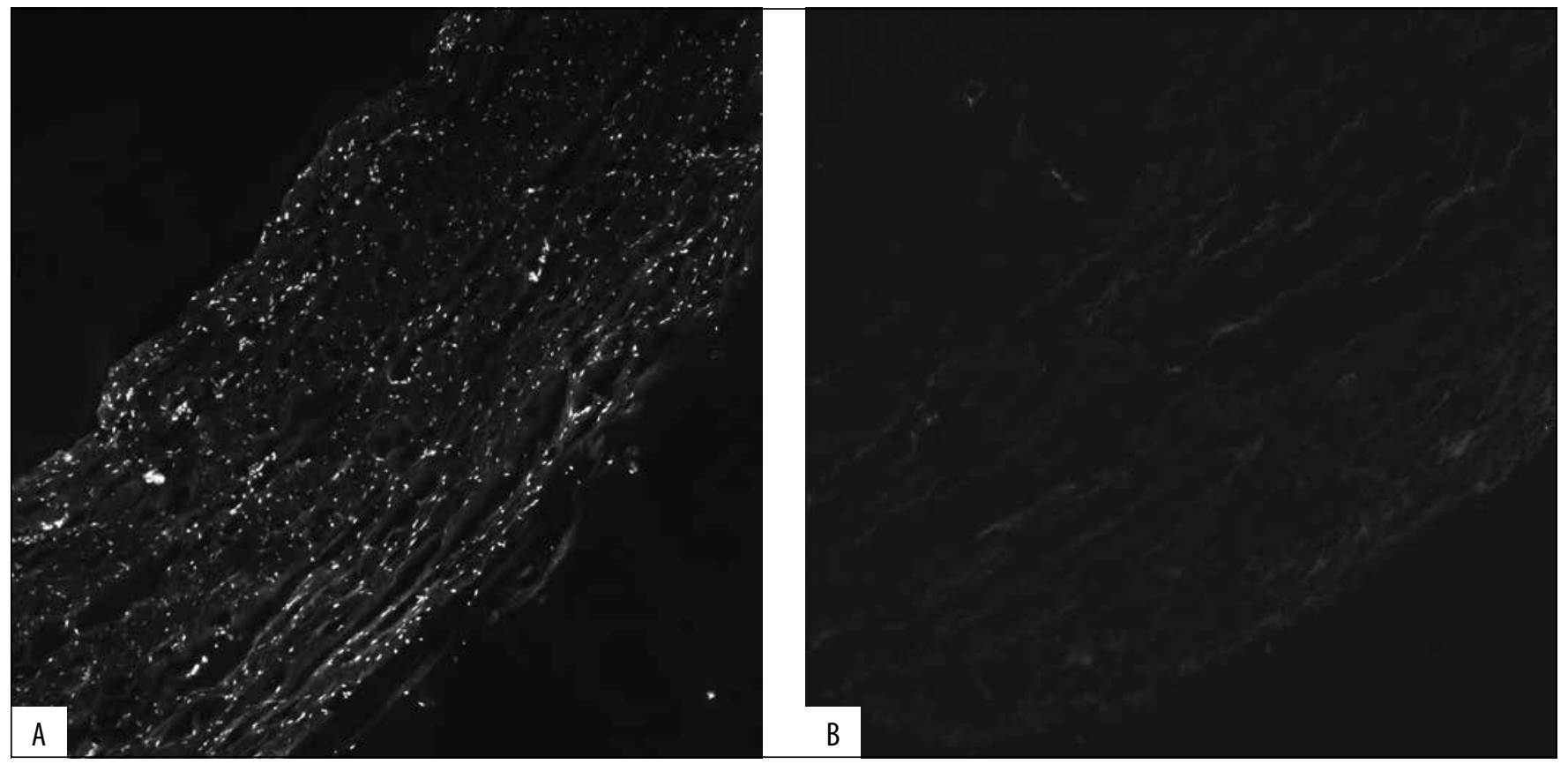

Fig. 2. Micrographs of histological sections of native and decellularized bovine pericardium; DAPI, fluorescence microscopy, x200. A - availability of nuclear fluorescence in native bovine pericardium (control group); $B$ - absence of nuclear fluorescence in decellularized by $0.1 \%$ SDS solution BP (experimental group).

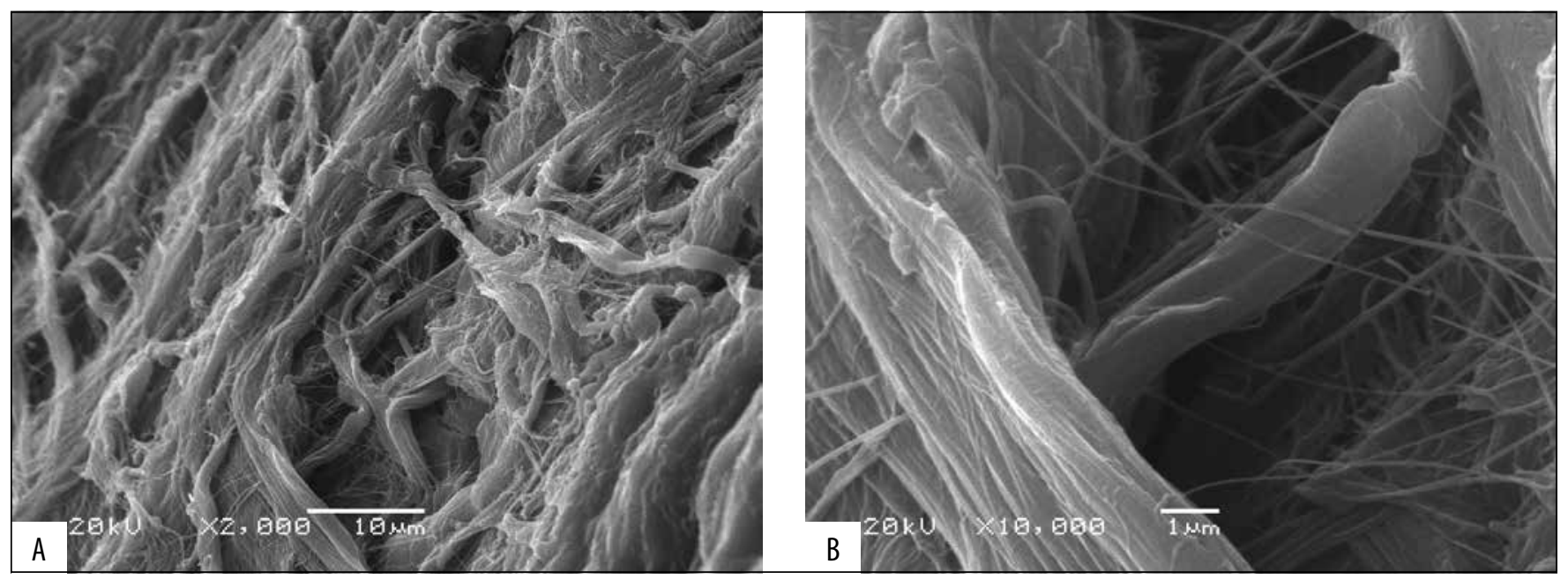

Fig. 3. Scanning electron micrographs. A — control group (native pericardium); B - experimental group (0.1\% solution of SDS) 
Table I. Comparative evaluation of native and decellularized bovine pericardium

\begin{tabular}{ccc}
\hline Research & Control group & Experimental group \\
\hline $\begin{array}{c}\text { Average DNA content } \\
(\mathrm{ng} / \mathrm{mg}), n=5\end{array}$ & $1436 \pm 116,8$ & $0,5 \pm 0,45^{*}$ \\
\hline $\begin{array}{c}\text { Longitudinal tissue testing } \\
\text { Fmax, maximal tensile strength (kgf) }\end{array}$ & $6,84 \pm 0,69$ & $9,55 \pm 0,65^{*}$ \\
\hline $\begin{array}{c}\text { Transverse tissue testing, } \\
\text { Fmax, maximal tensile strength (kgf) }\end{array}$ & $3,78 \pm 0,36$ & $4,56 \pm 0,37^{*}$ \\
\hline
\end{tabular}

${ }^{*}$ statistically significant compared with the control group $(\mathrm{P}<0.05)$

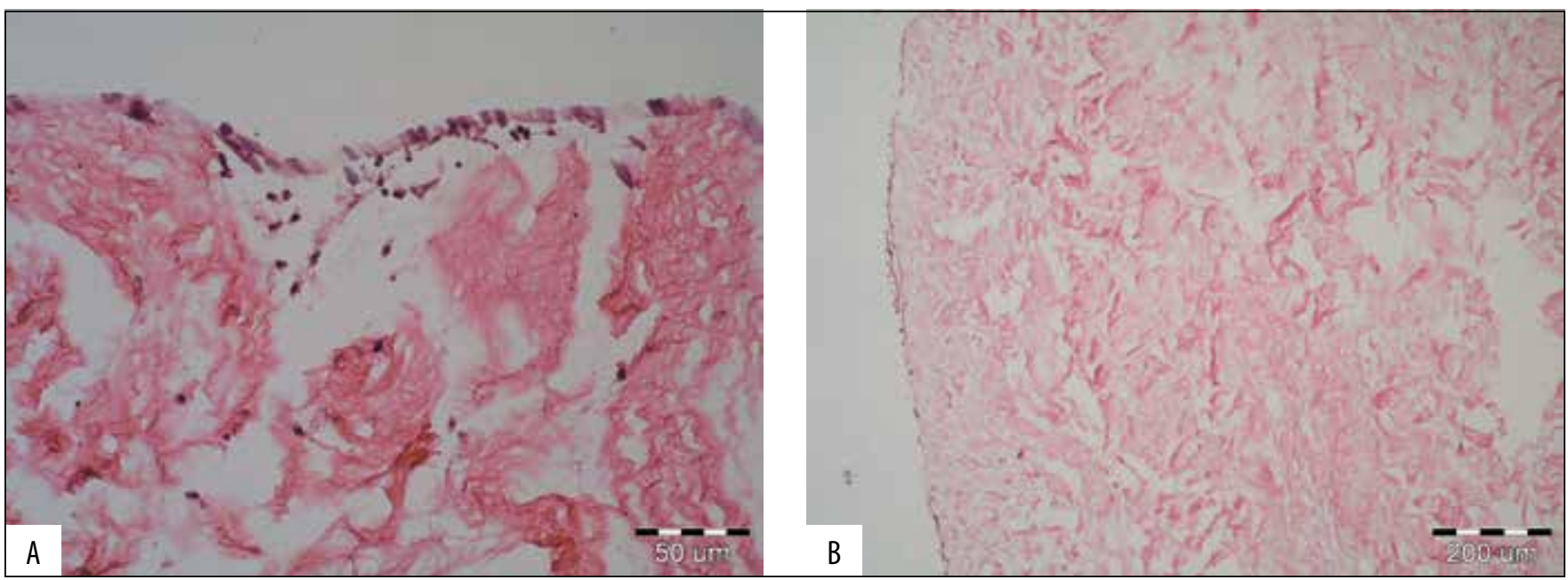

Fig. 4. Histological examination of experimental group (0.1\% SDS) after 2 months of cultivation (Hematoxylin-eosin, light microscopy).
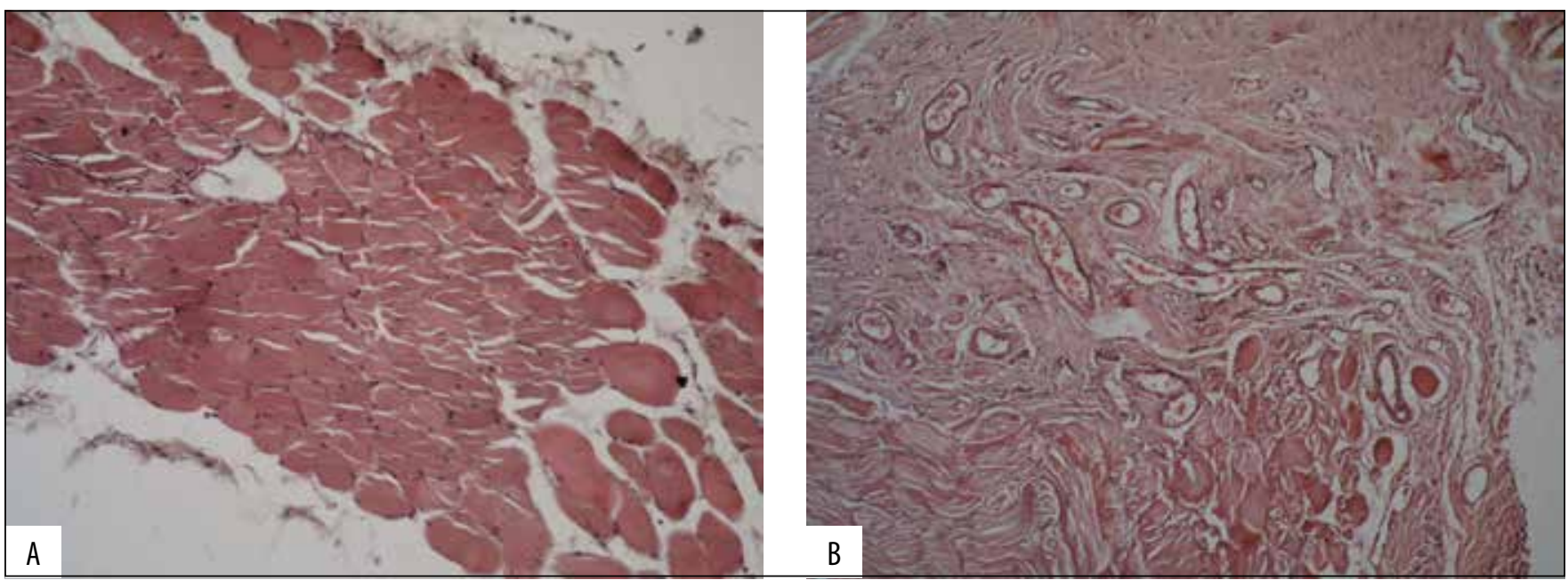

Fig. 5. Micrographs of histological sections in 3 months after subcutaneous implantation in rats; light microscopy, hematoxylin/eosin staining, $\times 200$. A no visible implanted native pericardium, swelling of muscle tissue with leukocyte infiltration (black arrows); B - the formation of immature connective tissue over the entire surface of the graft

\section{STATISTICAL ANALYSIS}

The analysis of the research results was carried out using biostatistical methods [9]. For quantitative values, the normality distribution was analyzed using the Shapiro-Wilk test. The mean value $(\mathrm{M})$ and standard deviation $( \pm \mathrm{SD})$ were calculated. To estimate the mean value, its $95 \%$ confidence interval $(95 \% \mathrm{CI})$ was calculated. For qualitative values, the frequency (\%) and, if necessary, 95\% CI were calculated. When comparing quantitative parameters in more than two groups, one-way ANOVA was used [9], posteriori comparisons were carried out using Scheffe Test (The distribution law did not differ from normal). To compare qualitative parameters, the chi-square test was used, posteriori comparisons for more than two groups were carried out taking into account the Bonferroni correction [9]. In the analysis, the criteria for a bilateral critical area were used, the critical level of significance was 0.05 . Statistical analysis of the research results was carried out in the statistical package EZR v. 1.54 (Saitama Medical Center, Jichi Medical University, Saitama, Japan, 2020) [10], which 
provides a graphical interface to $\mathrm{R}$ (The $\mathrm{R}$ Foundation for Statistical Computing, Vienna, Austria).

\section{RESULTS}

It is known that cellular components, including nucleic acids of xenografts, are strong antigens that trigger immunological reactions in the recipient provoking graft rejection. A decellularization protocol is considered to be effective in removing all cell components and nucleic residues [11]. To assess the decellularization, examination of samples stained with hemotoxylin-eosin and by the DAPI method was performed. Staining with hematoxylin and eosin revealed the presence of visible cell nuclei colored in violet in native pericardium of the control group (Fig. 1). At the same time, histological analysis showed that decellularized pericardial tissues retained the ECM components without cells or nuclei.

Additionally, the absence of relevant DAPI staining confirmed that most cellular nuclear material was removed after emulsification with SDS detergent $(\mathrm{P}<0.05,95 \%$ CI $84.3 \%-100 \%)$. The aforementioned could be clearly visualized by microscopic examination of DAPI samples (Fig. 2). We observed the absence of nuclear elements in expiremental group.

Qualitative microstructure analysis of SEM images also confirmed no obvious difference in the structure and distribution between the collagen and elastin fibers of the decellularized extracellular matrix and the native bovine pericardium (Fig. 3).

In the samples of the experimental group, the DNA concentration was estimated at the level of $3 \mathrm{ng} / \mathrm{mg}$ on the 35 th day of decellularization (Table 1). Thus, the degree of matrix purification of decellularized bovine pericardium from nucleic acid residues was $99.8 \%$ compared to native samples. A statistically significant difference was found between the DNA concentrations of the experimental and control groups $(\mathrm{P}<0.05)$.

The study of biomechanical properties showed that the decellularized matrix not only did not change its natural properties, but also gained greater strength after the process of purification and cross-linking. This is evidenced by an increase almost 2 times of the maximal tensile strength value in the samples of the experimental group by longitudinal tissue testing (Table I).

The cytotoxicity study of the decellularized extracellular matrix showed that after two months of cultivation the culture of human fibroblast cells formed monolayer on the surface of the BP sample. Some groups of fibroblasts penetrated to a depth of $350 \mu \mathrm{m}$ of low density fiber bundles (Fig. 4).

The ultimate goal of implantation is bioimplant integration into the host tissue with its subsequent regeneration [12]. Fig. 5 presents a histological examination of the explanted pericardium in control rats implanted with untreated/native BP. As expected, the pericardium is completely degraded and eliminated remaining only connective and muscle tissues. The tissue is infiltrated with leukocytes indicating inflammatory processes in the area.
At the same time, the histology data indicate successful biointegration of the implant in the rats of the experimental group in comparison with the control (Fig. 5). In the tissues, implant replacement with growing immature connective tissue was noted. In the area of implant, the increased vascularization of connective tissue is also observed, capillaries are formed, which are filled with erythrocytes. There was a lower level of macrophages and monocytes filtration in decellularized tissues of the pericardium compared to non decellularized tissues of the control group $(\mathrm{P}<0.05)$.

\section{DISCUSSION}

The result of this study was obtaining a xenograft scaffold with biomechanical and biological characteristics similar to the native BP. SDS was used in the decellularization process. It is well known that SDS is an ionic detergent, capable of binding to collagen fibers, destroying them and promoting swelling of the tissue, caused by a potential break in hydrogen bonds of the collagen fibers [11, 13]. SDS has been reported to interact strongly with the ECM proteins, making its complete removal challenging [14]. Ning Lia et al. also noted that residual SDS in decellularized tissues could result in an insufficient repopulation with the host cells after implantation, causing a lower durability of the implant and inhibiting growth. This was clearly correlated in rat implantation studies, where peri-implant necrosis was found around the 1\% SDS-treated implants [15].

Nevertheless, the literature confirms the effective use of this detergent, aiming to solubilize the cytoplasmic and nuclear elements while maintaining structure-function properties and recellularization potential of the matrix. This study confirms the hypothesis and demonstrates the effective use of low-concentration $0.1 \%$ SDS detergent and EDC/NHS cross-linking for decellularization of the BP. Tran Ha Le Bao et al. also showed that $0.1 \%$ SDS solution comparing to $0.3 \%$ or $0.5 \%$ SDS is more appropriate for porcine pericardial decellularization due to better preservation of the scaffold biological properties [16].

The microstructure analysis of hematoxylin-eosin and SEM images also showed the absence of any changes in collagen structure. Based on these facts, we confirmed hypothesis that the application of SDS at low concentration $(0.1 \%)$ is enough for the effective decellularization. Surprising fact was observed that the decellularized BP had higher biomechanical characteristics comparing the native pericardium. Some scientists reported that collagen fibrils are more densely packed after crosslinking with $\mathrm{EDC} / \mathrm{NHS}$ and have a more uniform structure comparing to noncrosslinked ones [17]. Besides, the EDC-crosslinked scaffolds possessed excellent mechanical property and biocompatibility.

Earlier studies have reported the cytotoxic nature of glutaraldehyde-treated tissue without indicating which fraction is cytotoxic [4]. In this case we used glutaraldehyde-free cross-linking. We noticed not only the absence of scaffold toxic effects on fibroblasts cells, but an increase 
of cell concentration on decellularized matrix. At the same time, histological data indicate successful integration of the implant in rats.

\section{CONCLUSIONS}

BP was successfully decellularized with additional application of cross-linking agent NHC/EDC maintaining structure-function properties and recellularization potential. Overall, BP tissue decellularized with $0.1 \%$ SDS and NHS/ EDC cross-linking is promising in the manufacturing of tissue-engineered materials for cardiac surgery.

\section{REFERENCES}

1. Pawan K.C., Hong Y., Zhang G. Cardiac tissue-derived extracellular matrix scaffolds for myocardial repair: advantages and challenges. Regen Biomater. 2019; 6(4): 185-199. doi: 10.1093/rb/rbz017.

2. Sarig U., Au-Yeung G.C.T., Wang Y. et al. Thick acellular heart extracellular matrix with inherent vasculature: a potential platform for myocardial tissue regeneration. Tissue Eng Part A. 2012;18:2125-37.

3. Gratzer P.F., Harrison R.D., Woods T. Matrix alteration and not residual sodium dodecyl sulfate cytotoxicity affects the cellular repopulation of a Decellularized matrix. Tissue Eng. 2006;12:2975.

4. Gendler E., Gendler S., Nimmi M.E. Toxic reactions evoked by glutaraldehyde fixed pericardium and cardiac valve tissue bioprostheses. J Biomed Mater Res. 1984;18:727-36.

5. Choe J.A., Jana S., Tefft B.J. et al. Biomaterial characterization of offthe-shelf decellularized porcine pericardial tissue for use in prosthetic valvular applications.J Tissue Eng Regen Med. 2018;12(7): 1608-1620. doi: 10.1002/term.2686.

6. Park S., Kim S.H., Lim H.G. et al. The Anti-calcification Effect of Dithiobispropionimidate, Carbodiimide and Ultraviolet Irradiation Cross-linking Compared to Glutaraldehyde in Rabbit Implantation Models. Korean JThorac Cardiovasc Surg. 2013;46(1):1-13. doi: 10.5090/ kjtcs.2013.46.1.1.

7. Vunjak-Novakovic G., Freshney R.I. Culture of Cells for Tissue Engineering. $2006.536 \mathrm{p}$.

8. Korzhevsky D. E. Application of hematoxylin in histological technique. Morphology. 2007; 132(6):77-82. (in Russian).

9. Guryanov V.G., Lyakh Yu. E., Pariy V.D. et al. Tcekhmister Handbook of Biostatistics. Analysis of the results of medical research in the package EZR (R - statistics). Textbook. - K.:Vistka; 2018, 208 p.

10. Kanda Y. Investigation of the freely available easy-to-use software'EZR' for medical statistics. Bone Marrow Transplant. 2013;48:452-458.

11. Gilbert W.T., Sellaro L.T., Badylak F.S. Decellularization of tissues and organs. Biomaterials. 2006;27:3675-3683. doi:10.1016/j. biomaterials.2006.02.014.

12. Rakhmatia Y.D., Ayukawa Y., Furuhashi A., Koyano K. Current barrier membranes:titanium mesh and other membranes for guided bone regeneration in dental applications. J Prosthodont Res. 2013;57:3-14. doi:pmid:23347794. (in Russian).
13. Oswal D., Korossis S., Mirsadraee S. et al. Biomechanical characterization of decellularized and cross-liked bovine pericardium. J. Heart Valve Dis. 2007;16:165-174.

14. Andre'e B., Bela K., Horvath T. et al. Successful re-endothelialization of a perfusable biological vascularized matrix (BioVaM) for the generation of 3D artificial cardiac tissue. Basic Res Cardiol. 2014;109:441.

15. Lia N., Lia Y., Gong D. et al. Efficient decellularization for bovine pericardium with extracellular matrix preservation and good biocompatibility. Interactive CardioVascular and Thoracic Surgery 2018;26:68-776. doi:10.1093/icvts/ivx416.

16. Tran H.L.B., Dihn T.H., Nguyen T.N. et. al. Preparation and characterization of acellular porcine pericardium for cardiovascular surgery. Turk J Biol. 2016;40:1243-1250. doi:10.3906/biy-1510-44.

17. Nong L.M., Zhou D., Zheng D. et al. The effect of different cross-linking conditions of EDC/NHS on type II collagen scaffolds: an in vitro evaluation. Cell and Tissue Banking. 2019;20:557-568.

\section{ORCID and contributionship:}

Nataliia V. Shchotkina: 0000-0002-8564-5881 ${ }^{B, D}$

Anatoliy A. Sokol: 0000-0002-4232-4025 C,E

Oleksandr Yu. Galkin: 0000-0002-5309-6099 A, F

Glib I. Yemets: 0000-0002-6139-6235 ${ }^{E}$

Liudmyla V. Dolinchuk: 0000-0003-3006-0832 ${ }^{E}$

Nadiia M. Rudenko: 0000-0002-1681-598X ${ }^{F}$

Iliia M. Yemets: 0000-0002-1893-0164 A,F

\section{Conflict of interest:}

The Authors declare no conflict of interest.

\section{CORRESPONDING AUTHOR Nataliia V. Shchotkina}

Center for Pediatric Cardiology and Cardio Surgery

24 Yuri llyenko st., 04050 Kyiv, Ukraine

tel: +380502599672

e-mail: carditissue@gmail.com

Received: 10.11 .2020

Accepted: 08.03.2021

A - Work concept and design, B - Data collection and analysis, C - Responsibility for statistical analysis, D-Writing the article, $\mathbf{E}$-Critical review, $\mathbf{F}$ - Final approval of the article 